\begin{tabular}{|lcc|}
\hline \multicolumn{3}{|c|}{ TOTOBUANG } \\
\hline Volume 5 & Nomor 1, Juni 2017 & Halaman 149—161 \\
\hline
\end{tabular}

\title{
MITOS-MITOS BERBASIS SUNGAI DALAM CERITA RAKYAT DI KALIMANTAN SELATAN \\ (Associated with River Myths in The South Kalimantan Folklore)
}

\author{
Agus Yulianto \\ Balai Bahasa Kalimantan Selatan \\ Jalan A. Yani, Km 32,2 Banjarbaru, Kalimantan Selatan \\ Pos-el: agusb.indo@gmail.com
}

(Diterima: 30 Maret 2017; Direvisi: 31 Maret 2017; Disetujui: 5 Juni 2017)

\begin{abstract}
For the people of South Kalimantan, river-based myths provide awareness to make friends with rivers. The aim of this study was to understand the form of myths found in the South Kalimantan's folklor and itsmeaning which dealing with river. The problem in this research is how is the form and what is the meaning of those folklores. This study used a qualitative descriptive method with literature review. Based on theanalysisresults, the form of myths in the South Kalimantan folklore related with the emergence of figures and the presence of certain animals, while the meaning of the myths related with the presence of figures in the myths itself.
\end{abstract}

Keywords: myths, folklore, South Kalimantan

Abstrak
Bagi masyarakat Kalimantan Selatan, mitos berbasis sungai memberikan kesadaran untuk bersahabat dengan sungai. Tujuan penelitian ini ialah untuk mengetahui wujud mitos-mitos berbasis sungai yang terdapat dalam cerita rakyat Kalimantan Selatan serta makna yang terkandung dalam mitosmitos berbasis sungai tersebut. Masalah dalam penelitian ini adalah bagaimana wujud mitos-mitos berbasis sungai yang terdapat dalam cerita rakyat Kalimantan Selatan dan apa makna yang terkandung dalam mitos-mitos berbasis sungai tersebut. Kajian ini menggunakan metode deskriptif kualitatif dengan teknik kajian pustaka.Berdasarkan hasil analisis dapat diketahui bahwa wujud mitos-mitos dalam cerita rakyat Kalimantan selatan dapat berupa kelahiran tokoh dan keberadaan binatang tertentu serta maknamakna mitos berkaitan dengan keberadaan tokoh-tokoh mitos tersebut.

Kata-kata kunci: mitos, cerita rakyat, Kalimantan Selatan

\section{PENDAHULUAN}

Kalimantan Selatan adalah sebuah provinsi yang memiliki begitu banyak sungai dalam wilayah teritorinya. Oleh sebab itu, tidak heran bila Kota Banjarmasin sebagai Ibu Kota Provinsi Kalimantan Selatan mendapat julukan "Kota Seribu Sungai."

Kehidupan sungai telah menjadi bagian integral dari masyarakat Kalimantan Selatan. Dahulu keberadaan sungai bahkan telah menjadi urat nadi bagi kehidupan masyarakat di Kalimantan Selatan. Baik sebagai sarana transportasi, ekonomi, sosial dan budaya. Oleh sebab itu tidak heran bila banyak cerita-cerita rakyat yang lahir di Kalimantan Selatan menjadikan sungai sebagai basis penceritaan. Banyak bagian dari alur dan latar dalam cerita rakyat di Kalimantan Selatan yang menjadikan sungai sebagai basisnya.

Kisah-kisah mitos berbasis sungai yang ada dalam cerita-cerita rakyat di Kalimantan Selatan secara langsung atau pun tidak langsung mengajak para pembacanya untuk merawat dan melestarikan keberadaan sungai yang menjadi nadi penting bagi kehidupan masyarakat itu sendiri. Sungai-sungai yang dahulu lebar dan dalam lambat laun mengalami pendangkalan dan menjadi 
kotor. Hal itu salah satunya disebabkan masyarakat membuang sampah sembarangan dan terkadang membangun bangunan yang terletak di pinggir-pinggir sungai yang lambat laun mengganggu aliran sungai itu sendiri. Selain itu pembangunan jembatan yang tanpa konsep dapat membuat lalu lintas perahuperahu yang berada di atas sungai menjadi terganggu. Jembatan-jembatan yang dibangun terlalu rendah membuat perahu-perahu yang agak besar tidak dapat lewat karena terhalang oleh jembatan tersebut.

Di sisi yang lain masyarakat di Kalimantan Selatan juga berkeyakinan bahwa mitos memiliki relasi dan korelasi yang kuat untuk selalu menyadarkan masyarakat mengenai betapa pentingnya keberadaan sungai bagi kehidupan mereka. Oleh sebab itu keberadaan mitos tersebut sedikit banyak memberikan kesadaran kepada masyarakat untuk selalu bersikap bersahabat dengan sungai.

Penelitian-penelitian yang pernah dilakukan menyangkut mitos-mitos di Kalimantan Selatan antara lain:

1. FudiatSuryadikara, dkk (2002) yang berjudul Mitos dalam Hikayat Lambung Mangkurat.

2. Saefuddin (2003) yang berjudul Struktur Mite dalam Sastra Lisan Banjar.

3. Rafiek (2010) yang berjudul Mitos Raja dalam Hikayat Raja Banjar.

Penelitian-penelitian yang pernah dilakukan sebelumnya ini membahas mitos-mitos yang terdapat dalam cerita rakyat Kalimantan Selatan yang tidak berkaitan dengan sungai. Penelitian tentang mitos-mitos yang berbasis sungai belum pernah dilakukan.

Atas dasar pemikiran itulah maka masalah dalam penelitian ini adalah bagaimana wujud mitos-mitos berbasis sungai yang terdapat dalam cerita rakyat Kalimantan Selatan dan apa makna yang terkandung dalam mitos-mitos berbasis sungai tersebut. Dengan demikian tujuan penelitian ini adalah untuk mengetahui wujud mitos-mitos berbasis sungai yang terdapat dalam cerita rakyat Kalimantan Selatan serta makna yang terkandung dalam mitos-mitos berbasis sungai tersebut. Dengan demikian, penelitian ini sangat penting untuk dilakukan untuk mengetahui wujud-wujud mitos berbasis sungai dan makna yang dikandungnya.

\section{LANDASAN TEORI}

Dalam bagian ini akan dijelaskan tiga konsep yang mendasari penelitian, yaitu sungai, mitos dan makna simbol dari mitos itu sendiri.

Sungai merupakan aset yang sangat penting bagi kehidupan masyarakat di Kalimantan Selatan pada umumnya. Keberadaan sungai sudah menjadi bagian integral bagi kehidupan masyarakat dan sudah menjadi bagian dari kebudayaan masyarakat Kalimantan Selatan. Menurut Kamus Besar Bahasa Indonesia (2014:1104) sungai mengandung arti sebagai aliran air yang besar (biasanya buatan alam). Menurut Soft Ilmu sungai adalah air tawar dari sumber alamiah yang mengalir dari tempat yang lebih tinggi ke tempat yang lebih rendah dan menuju atau bermuara ke laut, danau atau sungai yang lebih besar. Arus air di bagian hulu sungai (umumnya terletak di daerah pegunungan) biasanya lebih deras dibandingkan dengan arus sungai di bagian hilir. Aliran sungai seringkali berliku-liku karena terjadinya proses pengikisan dan pengendapan di sepanjang sungai. Sungai merupakan jalan air alami. mengalir menuju samudera, danau atau laut, atau ke sungai yang lain. Sungai juga salah satu bagian dari siklus hidrologi. (www.softilmu.com.Geografi).

Bascom (dalam Danandjaja, 2002:50) menjelaskan mitos atau mite adalah cerita prosa rakyat yang dianggap benar-benar terjadi serta dianggap suci sang empunya cerita. Selanjutnya Bascom (dalam Danandjaja, 2002:51) menjelaskan bahwa mite pada umumnya 
mengisahkan terjadinya alam semesta, dunia, manusia pertama, terjadinya maut, bentuk khas binatang, bentuk topografi, gejala alam, dan sebagainya. Mite juga mengisahkan petualangan para dewa, kisah percintaan mereka, hubungan kekerabatan mereka, kisah perang mereka dan sebagainya.

Napitupulu (dalam Kompas, 22 Desember 2008) menyebut mitos sebagai bagian dari tradisi lisan yang mengandung kearifan lokal yang berisi ajaran kebajikan dan keharmonian. Daeng (2000:103) menyatakan bahwa dalam masyarakat tradisional mitos memainkan peran sebagai pedoman tingkah laku masyarakat yang berjalan baik karena diyakini mendapat campur tangan leluhur. Wouden (1985:131) mengindentikkan mitos dengan cerita rakyat yang hidup di dalam masyarakat tradisional, sebuah cerita yang bernuansa kosmis. Lebih jauh Hasanuddin (2010:3) mengindentikkan mitos sebagai satu unsur tradisi sehingga layak dianggap sebagai sistem komunikasi yang memberikan pesan berkenaan dengan aturan masa lalu, ide, ingatan, kenangan, atau keputusan yang diyakini. Selanjutnya Hasanuddin (2010:4) juga menyatakan mitos selalu berkaitan dengan keyakinan dan keyakinan berhubungan dengan kepercayaan serta kepercayaan bertolak dari tradisi dan kebiasaan.

Analisis makna dalam karya sastra tidak dapat dilepaskan dari sebuah pendekatan yang dinamakan semiotik. Secara etimologis istilah semiotika berasal dari bahasa Yunani "semeion" yang berarti 'tanda' (Sudjiman dan van Zoest, 1996:vii) atau seme,yang berarti "penafsir tanda" (Cobley danJansz, 1999:4) (dalam Sobur, 2004:16). Semiotika kemudian didefinisikan sebagai studi tentang tanda dan cara tanda-tanda itu bekerja.Tanda-tanda bahasa hanya merupakan salah satu kelompok tanda yang kita pergunakan. Kata-kata, tetapi juga kalimat-kalimat dan teks-teks termasuk tanda-tanda bahasa.
Ilmu semiotik menganggap bahwa fenomena sosial (masyarakat) dan kebudayaan itu merupakan tanda-tanda. Semiotik mempelajari sistem-sistem, aturan-aturan, konvensi-konvensi yang memungkinkan tanda-tanda tersebut mempunyai arti. Dalam bidang kritik sastra, penelitian semiotik meliputi analisis sastra sebagai sebuah penggunaan bahasa yang bergantung pada (sifat-sifat) yang menyebabkan bermacam-macam cara (modus) wacana mempunyai makna (Preminge, dkk. dalam Pradopo, 2002:67-68).

Berdasarkan objeknya, Peirce membagi tanda atas icon (ikon), index (indeks), dan symbol (simbol). Ikon adalah tanda yang hubungan antara penanda dan petandanya bersifat bersamaan bentuk alamiah. Dengan kata lain, ikon adalah hubungan antara tanda dan objek atau acuan yang bersifat kemiripan, misalnya foto. Indeks adalah tanda yang menunjukkan adanya hubungan alamiah antara tanda dan petanda yang bersifat kausal atau hubungan sebab akibat atau tanda yang langsung mengacu pada kenyataan; misalnya asap sebagai tanda adanya api. Simbol itu tanda yang tidak menunjukkan hubungan alamiah antara penanda dan petandanya. Hubungan antaranya bersifat arbitrer atau semau-maunya, hubungannya berdasarkan konvensi (perjanjian) masyarakat. Sebuah sistem tanda yang utama yang menggunakan lambang adalah bahasa. Arti simbol ditentukan oleh masyarakat. Untuk membedakan arti bahasa dan arti sastra dipergunakan istilah arti (meaning) untuk bahasa, dan makna (significance) untuk arti sastra.

Untuk menemukan makna yang dikandung dalam simbol-simbol mitos yang terdapat dalam tiap-tiap cerita rakyat terlebih dahulu dibuat diidentifikasi wujud mitos dalam tiap-tiap cerita. Kemudian, dilanjutkan pada analisis makna yang dikandung dalam simbolsimbol mitos yang terdapat dalam cerita 
dengan menempatkan karya pada konteksnya.

\section{METODE}

Penelitian ini menggunakan metode deskriptif kualitatif. Sunarto (2001:135) mengemukakan bahwa penelitian kualitatif bertujuan untuk mendeskripsikan dan menganalisis fenomena, peristiwa, aktivitas sosial, sikap, kepercayaan, persepsi, dan pemikiran orang secara individual maupun kelompok. Selain itu, menurut pendapat Bogdan dan Taylor (dalam Moleong, 2010:4) penelitian kualitatif adalah prosedur penelitian yang menghasilkan data deskriptif berupa katakata tertulis atau lisan tentang orangorang dan perilaku yang dapat diamati.

Menurut Semi (2012:23) metode deskriptif adalah metode yang dilakukan dengan tidak menggunakan angka-angka, tetapi menggunakan penghayatan terhadap interaksi antar konsep yang sedang dikaji secara empiris. Setelah itu dilakukan analisis isi dengan menggunakan semiotika untuk mengetahui makna mitos yang terdapat dalam tiap-tiap cerita.

Teknik penelitian yang digunakan adalah dengan mengunakan teknik studi pustaka. Peneliti mengumpulkan bahanbahan yang relevan dengan penelitian dari perpustakaan dan koleksi pribadi

\section{PEMBAHASAN}

Cerita-cerita rakyat yang ada di Kalimantan Selatan terkadang menjadikan sungai sebagai basis penceritaan. Hal itu dapat dimaklumi disebabkan geografi wilayah Kalimantan Selatan terdapat begitu banyak sungai. Keberadaan sungai-sungai tersebut melahirkan kreativitas imajinasi pengarang zaman dahulu untuk melahirkan karya sastra berupa cerita rakyat. Mitos-mitos berbasis sungai yang diselipkan dalam cerita-cerita rakyat itu membawa pesan kepada generasi berikut untuk dapat memelihara dan melestarikan kehidupan serta budaya masyarakat yang bersahabat dengan sungai. Berikut wujudwujud mitos berbasis sungai yang terdapat dalam cerita rakyat Kalimantan Selatan beserta makna simbol yang dikandungnya yang terdapat dalam Kisah Putri Junjung Buih, Asal Mula Terjadinya Sungai Barito, Kisah Sultan Suriansyah Membangun Masjid, Kisah Datu Kartamina, Si Manusia Buaya, dan Kisah Lok Si Naga.

\subsection{Kisah Putri Junjung Buih}

Kisah Putri Junjung Buih sangat terkenal di Kalimantan Selatan. Kisah ini menceritakan tentang asal mula kehadiran Putri Junjung Buih di Kerajaan Nagara Dipa yang berasal dari buih sungai. Kisah lengkap kehadiran atau terciptanya Putri Junjung Buih sebagai berikut.

Dahulu di Kalimantan, khususnya Kalimantan Selatan belum mempunyai bentuk pemerintahan yang tertata seperti sebuah bentuk kerajaan. Orang-orang yang ada di Kalimantan waktu itu hanya berupa kelompok-kelompok yang dinamakan bubuhan. Sejak kedatangan rombongan Ampu Jatmika dari Kerajaan Keling di Jawa barulah terbentuk kerajaan pertama yang bernama Nagara Dipa yang saat itu terletak di Kabupaten Hulu Sungai Utara.

Pada saat merasa akan menemui kematiannya, Ampu Jatmika berpesan kepada kedua anaknya yang bernama Ampu Mandastana dan Lambung Mangkurat untuk bertapa mencari seorang raja yang akan memerintah di Kerajaan Nagara Dipa. Ampu Jatmika tidak berkenan mewarisi tahta kerajaan kepada salah satu dari anaknya disebabkan merasa bahwa mereka bukan dari darah bangsawan, tetapi hanya keturunan seorang pedagang. Akhirnya Ampu Jatmika wafat dan Ampu Mandastana serta Lambung Mangkurat mulai bertapa mencari raja baru selama dua tahun. Ampu Mandastana bertapa di gua bawah tanah sedangkan Lambung Mangkurat bertapa di pusaran air sungai 
yang dalam. Rupanya yang berhasil mendapatkan raja baru adalah dari hasil pertapaan Lambung Mangkurat di pusaran air sungai. Hal itu terlihat dalam kutipan berikut.

"Pada waktu hari yang
ditentukan itu, maka Putri
Junjung Buih keluar dari
tengah pusaran air yang
berbuih. Putri muncul seperti
diangkat oleh buih yang besar
hingga sebesar gunung
besarnya. Di tengah-tengah
cahaya silau rang
menyilaukan, putri keluar
dengan wajah yang sangat
rupawan. Badannya putih
kuning seluruhnya, rambutnya
ikal mayang, hidung
mancung, mata terang
menderang, bulu matanya
hitam lentik. Ditambah
pulang pakaian kain
langgundi dengan selendang
yang serba kuning panjang,
menambah Putri Junjung Buih
kelihatan cantik tiada kira"
(Yulianto:69).

Setelah memerintah Kerajaan Nagara Dipa untuk beberapa lamanya, Putri Junjung Buih hendak dinikahkan oleh Lambung Mangkurat dengan seorang anak Raja Majapahit di tanah Jawa yang bernama Pangeran Suryanata. Mereka pun akhirnya menikah dan anak keturunan mereka nantinya akan menjadi raja-raja di Kerajaan Banjar.

"Tak lama setelah Putri Junjung Buih jadi raja putri di Nagara Dipa kemudian Lambung Mangkurat terpikir dalam hati, rasanya tidak cocok Putri Junjung Buih hidup sendirian saja, jika tidak berpasangan dengan raja juga. Lalu Lambung Mangkurat mengungkapkan buah pikirannya itu dengan raja Putri Junjung Buih. Sekalinya Raja Putri Junjung Buih menjawab:
"Aku mau saja kawin dengan anak raja Majapahit yang diperoleh dari pertapaan di benua seberang."

Malam berikutnya Lambung Mangkurat bermimpi menjumpai arwah bapaknya yang memberitahukan supaya Lambung Mangkurat pergi berangkat ke banua seberang mengambil anak raja hasil pertapaan itu. Anak raja hasil pertapaan itu bernama Radin Putra atau Pangeran Suryanata. Maka setelah itu pergilah Lambung Mangkurat membawa kapal kerajaan yang bernama $\mathrm{Si}$ Parabayaksa" (Yulianto:69).

\subsubsection{Makna Mitos}

Mitos yang menyatakan bahwa Putri Junjung Buih terlahir dari buih di sungai secara semiotik merupakan simbol yang memiliki beberapa makna, yaitu 1) Penguasa atau raja putri pertama merupakan putra daerah asli Kalimantan Selatan yang kelak akan menurunkan raja-raja di kerajaan-kerajaan yang ada wilayah Kalimantan. 2) Kelahiran sang putri dari buih air sungai menunjukkan kuatnya hubungan sosial budaya masyarakat Kalimantan Selatan dengan sungai.

Di sisi yang lain, suami Putri Junjung Buih yang berasal dari Kerajaan Majapahit yang bernama Suryanata secara semiotik juga memiliki makna, yaitu1) Penamaan tokoh putri dengan nama Junjung Buih secara tidak langsung mewakili unsur air (buih), sedangkan penamaan tokoh suami Junjung Buih dengan nama Surya (nata) mewakili unsur api (surya adalah matahari). Oleh sebab itu, perpaduan atau pernikahan mereka telah mewakili kosmologi masyarakat Kalimantan pada waktu itu berupa perpaduan antara panas dengan dingin atau dalam terminologi bangsa Tionghoa dengan istilah yin dan yang.

Yin-Yang atau Yin dan Yang adalah konsep dalam filosofi Tionghoa yang biasanya digunakan untuk 
mendeskripsikan sifat kekuatan yang saling berhubungan dan berlawanan di dunia ini dan bagaimana mereka saling membangun satu sama lain. Yin dan Yang biasanya dipakai untuk mendeskripsikan sifat yang saling berhubungan, berlawanan dan saling mengisi satu sama lain.

Yin lebih bersifat pasif, tenang, surga, bulan, air dan perempuan, simbol untuk kematian.Yang lebih bersifat aktif, bergerak, bumi, matahari, api, dan lakilaki, simbol untuk hidup.Yin berhubungan dengan air, bumi, bulan, feminitas dan malam hari. Yang berhubungan erat dengan api, langit, matahari, maskulinitas dan siang hari. Yin dan Yang merupakan sebuah gambaran nyata dari perputaran kehidupan dunia. Yin dan Yang memiliki dua arti, yaitu:

1. Sebagai sebuah ketenteraman dan kesederhanaan dalam menjalani kehidupan nyata.

2. Kedua adalah sebagai sebuah perputaran kehidupan dan keseimbangan hidup, artinya kehidupannya manusia tidak mungkin akan selalu berada dalam satu jalan saja. Hari ini kita mengalami kesusahan, besok bisa jadi kita akan mengalami sebuah kebahagiaan.

Dengan demikian, nenek moyang masyarakat Kalimantan Selatan pada zaman dahulu telah memiliki pemikiran yang sangat tinggi, terutama mengenai falsafah hidup mereka. Hal itu dibuktikan dengan sudah dikenal dan terdapatnya falsafah Yin dan Yangdalam cerita rakyat mereka.

\subsection{Asal Mula Terjadinya Sungai Barito.}

Sungai Barito adalah sungai terbesar yang berada di Kalimantan Selatan. Menurut sebuah riwayat terjadinya sungai Barito tidak terlepas dari kisah seorang anak yang bernama Bari dan kucingnya yang bernama Ito. Kisah lengkapnya sebagai berikut.
Ada sepasang suami istri yang telah lama berumah tangga. Akan tetapi, mereka belum juga dikaruniai seorang anak. Oleh sebab itu, mereka berdoa kepada Tuhan Yang Mahakuasa untuk dikaruniai seorang anak. Akhirnya pada suatu malam sang istri bermimpi didatangi seorang pertapa tua yang mengabarkan kepadanya bahwa mereka akan dikaruniai seorang putra. Akan tetapi, ada satu syarat yang diberikan pertapa tua itu, yaitu pada saat berumur sepuluh tahun, anak tersebut akan diambil kembali oleh pertapa tua.

Akhirnya ibu tersebut mengadung dan setelah mencapai usia sembilan bulan melahirkan seorang anak yang dinamakan Bari. Bari tumbuh menjadi anak yang baik dan bersahabat dengan seekor kucing yang dinamakan Ito. Tidak berapa lama waktu berselang kedua orang tua Bari meninggal dunia dan Bari akhirnya dirawat oleh bibinya. Sebelum meninggal orang tua Bari mewasiatkan agar Bari jangan bermain-main di tepi jurang. Hal itu disebabkan pada saat berumur sepuluh tahun Bari akan menemui ajalnya, sedangkan jurang tersebut didiami oleh seekor naga yang nantinya akan membunuh Bari. Benar saja akhirnya Bari jatuh kedalam jurang karena ingin menolong Ito, kucingnya, yang terjatuh lebih dahulu kedalam jurang tempat sang naga bersemayam.

Bibi Bari bersama warga desa mendatangi jurang untuk meminta agar sang naga melepaskan Bari dan Ito. Sang naga menolak permintaan tersebut, tetapi menyanggupi satu permintaan warga yang pasti akan dikabulkannya. Warga kemudian meminta agar jurang tempat naga tersebut berisi air dan menjadi sungai agar memudahkan aktivitas warga bila ingin menyeberang ke desa sebelah jurang. Permintaan itu dikabulkan sang naga. Hal itu terlihat dalam kutipan berikut.

"Kalau begitu tolong sebagai ganti pengurbanan keponakanku jadikanlah jurang 
ini menjadi sungai agar antara desa kami dan desa seberang ada sebuah penghubung." Kata bibi Bari yang diiyakan oleh kepala desa.

"Baiklah, tapi kalian harus pergi dari sini." Kata sang naga kembali ke dasar jurang.

Bibi Bari pun pulang
dengan hati yang pilu,
untung sang kepala desa
pandai menghibur sehingga
kesedihannya rak
berkurang. Setelah mereka
tiba di rumah tiba-tiba langit
menjadi mendung. Tak lama
kemudian terlihat kilat
bersambungan dengan suara
petir yang menggelegar,
hujan turun dengan
derasnya. Selama dua hari
berturut-turut warga desa
tidak bisa keluar rumah
karena hujan terus turun
dengan lebatnya.
Pada hari ketiga hujan
akhirnya berhenti dan warga
desa pun keluar dari rumah
mereka, dibawah pimpinan
kepala desa dan bibi Bari
mereka bersama-sama
menuju jurang. Tetapi
alangkah terkejutnya
mereka, karena jurang itu
kini berubah menjadi sebuah
sungai yang lebar dan
dalam" (Yulianto:40).

Warga desa kemudian menamakan sungai tersebut dengan nama Sungai Barito. Hal itu untuk mengenang pengorbanan Bari dan Ito yang telah diambil oleh sang naga.

\subsubsection{Makna Mitos}

Penggambaran atau hadirnya tokoh naga dari dasar jurang dalam cerita yang dapat berbicara dan bercakap-cakap dengan bibi Bari secara semiotik merupakan simbol yang mengandung makna tentang suatu budaya. Dalam budaya Kalimantan, khususnya suku Dayakdan suku Banjarnaga dianggap sebagai simbol alam bawah. Naga digambarkan hidup di dalam air atau tanah dan disebut sebagai Naga Lipat Bumi. Naga merupakan perwujudan dari tambun, yaitu makhluk yang hidup dalam air.

Menurut budaya Kalimantan, alam semesta merupakan perwujudan "Dwitunggal Semesta" yaitu alam atas yang dikuasai oleh Mahatala atau Pohotara, yang disimbolkan enggang gading (burung), sedangkan alam bawah dikuasai oleh Jata atau Juata yang disimbolkan sebagai naga (reptil). Alam atas bersifat panas (maskulin) sedangkan alam bawah bersifat dingin (feminim). Manusia hidup di antara keduanya.

Selain itu, proses berubahnya jurang menjadi sungai yang memerlukan hujan lebat secara semiotik juga merupakan simbol yang mengadung makna bahwa sesuatu hal itu terjadi berdasarkan hukum alam. Sang naga tidak serta-merta secara ajaib mengubah jurang menjadi sungai. Akan tetapi, tetap saja memerlukan proses yang alami, yaitu melalui perantara hujan lebat.

Penamaan sungai Barito di Kalimantan yang berasal dari penggabungan nama Bari dengan Ito secara semiotik merupakan simbol yang mengandung makna bahwa tidak ada pengorbanan yang tulus yang menjadi sia-sia di dunia ini. Pengorbanan tulus Bari untuk menyelamatkan Ito menjadikan nama mereka menjadi abadi dan terkenal sepanjang masa.

\subsection{Kisah Sultan Suriansyah Membangun Masjid}

Sultan Suriansyah adalah raja Kerajaan Banjar pertama yang memeluk agama Islam. Nama sebenarnya adalah Pangeran Samudra. Setelah memeluk agama Islam, Sultan Suriansyah berencana membangun masjid sebagai tempat umat Islam untuk melaksanakan 
ibadah secara bersama-sama. Akan tetapi, pada saat membangun masjid tersebut seringkali mendapat gangguan dari seekor buaya putih yang dikirim oleh Raden Temenggung dari Margasari, seteru Sultan Suriansyah. Kisah lengkapnya sebagai berikut.

Setelah masuk Islam, Sultan Suriansyah berencana untuk membangun masjid. Oleh sebab itu, Sultan Suriansyah memerintahkan Aria Malangkan untuk mencari kayu ulin yang akan digunakan sebagai soko guru atau tiang utama masjid. Setelah kayu ulin didapat, Sultan Suriansyah menetapkan hari pertama pembangunan masjid. Pada hari yang ditentukan, Sultan Suriansyah bersama masyarakat mulai bergotong royong membangun masjid. Masjid yang dibangun terletak dipinggir sungai. Pekerjaan pembangunan masjid dilakukan berhari-hari. Akan tetapi, terdapat keanehan pembangunan yang telah dilakukan dihari kemarin menjadi rusak pada hari ini. Hal itu terjadi berulang-ulang.

Sultan Suriansyah memerintahkan patihnya yang bernama Patih PanimbaSagara untuk mencari tahu penyebab kerusakan yang terjadi pada masjid yang sedang dibangun. Patih PanimbaSagara kemudian memerintahkan para buaya kuning untuk mencari tahu penyebab kerusakan masjid. Ternyata kerusakan yang terjadi pada masjid disebabkan ulah buaya putih suruhan Tumenggung dari Margasari. Hal itu terlihat dalam kutipan berikut.

"Setelah menerima perintah itu buaya kuning langsung saja memeriksa bagian bawah bangunan. Di bagian bawah bangunan ia bertemu dengan seekor buaya putih. Sebetulnya buaya putih tersebut adalah buaya pujaan dari Tumenggung di Margasari. Tumenggung tersebut kebetulan adalah paman dari Pangeran
Suriansyah. la merasa iri terhadap Pangeran Suriansyah. Untuk menggagalkan pembangunan masjid ia lalu menciptakan seekor buaya putih. Buaya putih itu diciptakan dengan kekuatan mantranya. Setelah jadi lalu buaya putih dikirim ke Kuin dengan tugas khusus merusak bangunan (Yulianto:13).”

Akhirnya terjadi pertempuran antara buaya kuning dengan buaya putih. Pertama-tama buaya kuning kalah oleh buaya putih. Akan tetapi, setelah mendapat bala bantuan dari para buaya kuning lainnya akhirnya buaya putih dapat dikalahkan dan pembangunan masjid dapat dilakukan lagi sampai selesai.

\subsubsection{Makna Mitos}

Buaya putih yang menjadi pujaan Temunggung secara semiotik merupakan simbol yang berbeda maknanya dengan buaya kuning, suruhan Patih PanimbaSagara. Kalau Patih PanimbaSagara yang mengendalikan buaya kuning (dunia bawah), sedangkan Temenggung yang dikuasai dunia bawah karena dia yang memuja buaya putih. Hal tersebut dapat dipahami jika dikaitkan dengan kenyataan bahwa TemenggungMargasari belum masuk Islam. Oleh sebab itu, ia masih menyandarkan dirinya pada kekuatankekuatan di alam raya ini (politeisme) yang berbeda dengan Islam yang hanya menyandarkan dirinya kepada Allah swt.

Buaya putih itu sendiri merupakan simbol yang mengandung makna adanya penguasa air (dunia bawah/alam gaib) sebagai ciri dari masyarakat Banjar yang sangat erat kehidupannya dengan sungai, sedangkan warna putih pada buaya tersebut merupakan simbol yang 
mengandung makna bahwa buaya tersebut adalah buaya jadi-jadian dari kalangan bangsawan Banjar pra-Islam. Buaya putih yang identik dengan buaya jadi-jadian sama dengan buaya putih yang ada di Jawa. Hal itu disebabkan warna buaya yang sebenarnya adalah hitam keabu-abuan.

Patih PanimbaSagara kemudian memerintahkan buaya kuning untuk menghadapi buaya putih. Akan tetapi, ternyata buaya kuning kalah. Oleh sebab itu buaya kuning meminta bala bantuan kepada Patih PanimbaSagara.

"Gusti", katanya setelah berhadapan dengan tuannya. "Hamba tidak sanggup melawan buaya putih itu kalau hanya seorang diri saja. Buaya putih itu ternyata sangat kuat Gusti". "Kalau engkau tidak sanggup melawannya sendirian, maka bawalah teman-temanmu besok malam. Kau boleh keroyok buaya putih itu". Ujar PanimbaSagara.

Menerima perintah demikian, buaya kuning pun segera berlalu dan mengumpulkan kawankawannya. Pada esok malamnya ia pun kembali bersiaga di bangunan masjid dengan lima belas ekor buaya kuning lainnya. Ketika buaya putih muncul dan siap akan merusak bangunan maka buaya-buaya kuning segera menyerangnya (Yulianto:14).

Akibat dari pertempuran tersebut sungai Kuin bertambah lebar karena tebing-tebingnya kena hempasan badanbadan buaya yang sedang bertempur. Hal ini secara semiotik merupakan simbol yang mengandung makna adanya pengaruh yang nyata antara dunia gaib dengan dunia nyata. Buaya-buaya yang nota bene buaya-buaya jadi-jadian ternyata dapat mengubah topografi sungai menjadi lebih lebar.

Pertempuran tersebut akhirnya dimenangkan oleh buaya-buaya kuning sedangkan buaya putih mati. Dengan demikian pembangunan masjid dapat terus dilanjutkan. Setelah tiga puluh hari, pembangunan masjid selesai dikerjakan.

\subsection{Kisah Datu Kartamina, Si Manusia Buaya}

Pada abad ke-14 di Kecamatan Kalua, Kabupaten Tabalong, Provinsi Kalimantan Selatan hiduplah seorang Datu yang bernama Kartamina. Menurut sahibul hikayat beliau berasal dari keturunan Raja Gagalang Kalua. Beliau mempunyai watak pemberani dan agak liar. Kebiasaan beliau adalah suka merendam kaki ke air.

Datu Kartamina mempunyai kesaktian dapat menciptakan buaya dengan mengubah batang korek api menjadi buaya. Korek api itu beliau ambil sebatang dan diletakkan di telapak tangan kanan sambil mulut komat-kamit membaca mantra:

Oh, Gusti di alam hening

Hamba bermohon dengan bening

Ubahlah bilah ini menjadi buaya kuning

Bernyawa

Berenang-renang

Menjaga

keamanan

Selanjutnya beliau pejamkan mata beberapa lama sementara mulut terus berkomat-kamit, maka batang korek api itupun berubah menjadi buaya, mulamula kecil seperti cecak kemudian akan menjadi besar apabila dimasukan ke dalam sungai.

Selain itu Datu Kartamina bisa mengubah diri menjadi buaya kuning. Kalau sudah menjadi buaya, beliau berdiam didasar sungai dan sesekali timbul ke permukaan sungai. Kalau buaya 
itu timbul di permukaan sungai orangorang yang melihatnya akan merasa ketakutan karena bentuknya tidak seperti buaya kebanyakan, bentuk buaya kuning ini besar seperti pohon aren (enau) sangat menyeramkan.

Jika beliau ingin kembali menjadi manusia, kelihatanlah air sungai beriakberiak dan berbuih tebal, kemudian muncul buaya kuning dipermukaan sungai dan terus naik ke darat kemudian buaya kuning itu lambat laun berubah kembali menjadi manusia seperti sedia kala.

Datu Kartamina bersahabat dengan Raja dari Kerajaan Negara Dipa, Amuntai. Karena saking akrabnya mereka sering bertemu dan bercengkerama, terkadang Datu Kartamina datang ke Amuntai untuk bertemu dan terkadang Raja Negara Dipa yang datang ke Kalua.

Suatu hari sang raja datang berkunjung ke Kalua untuk melepas rindu pada sahabatnya Datu Kartamina karena lebih kurang dua bulan tidak bertemu, setelah tiba dirumah Datu Kartamina, sang raja mengetuk pintu rumahnya, namun setelah diketuk beberapa kali tetap tidak ada jawaban maka sang raja bertanya kepada tetangga disebelah rumah Datu Kartamina. Oleh tetangga di sebelah rumah beliau berkata bahwa tadi beliau sedang berada di sungai.

Sang Raja berjalan menuju ke sungai sebagaimana yang telah dikatakan oleh tetangga Datu Kartamina namun tidak menemukannya. Lalu sang raja berteriak-teriak memanggil sahabatnya tersebut dari pinggir sungai. Sebenarnya sang raja tidak mengetahui kemampuan yang dimiliki oleh Datu Kartamina yang dapat berubah wujud menjadi seekor buaya. Hal itu terlihat dalam kutipan berikut.

"Kartamina ...! Kartamina
... Di mana kau? Aku
sahabatmu ingin bertemu"
kata sang raja.Setelah
beberapa kali berteriak
memanggil, tak lama

\begin{abstract}
kemudian air disungai dihadapan sang raja menjadi beriak-riak dan berbuih tebal, kemudian muncullah buaya kuning yang menyeramkan sebesar pohon enau. Melihat pemandangan yang ada di hadapannya sang raja terkejut dan takut yang luar biasa.Sebelumnya Datu Kartamina tidak mengatakan kepada temannya bahwa ia dapat menjadi buaya kuning, belum lagi kejutan yang hilang dan takut, raja telah menyerang lagi dengan suara-suara buaya yang memanggil namanya."Jangan takut sahabatku, akulah Kartamina yang kau cari” kata buaya itu. Setelah naik ke darat berubahlah buaya kuning itu menjadi Datu Kartamina yang asli" (Yulianto:33).
\end{abstract}

Sejak kejadian itu sang raja semakin senang bersahabat dan bergaul dengan Datu Kartamina sang raja pun sangat menghormati Datu Kartamina.

\subsubsection{Makna Mitos}

Buaya dalam kehidupan masyarakat Kalimantan Selatan yang berbasis sungai merupakan binatang yang sudah terbiasa hadir dalam kehidupan mereka. Akan tetapi, saat ini sudah sulit untuk menjumpai buaya di sungai-sungai. Hal itu disebabkan perburuan dan pembunuhan terhadap buaya itu sendiri yang merupakan jenis binatang yang berbahaya bagi manusia.

Dalam budaya masyarakat di Kalimantan Selatan mitos yang menyatakan manusia dapat menciptakan dan berubah wujud menjadi buaya sudah merupakan pengetahuan yang bersifat umum. 
Kemampuan Datu Kartamina yang dapat mengubah batang korek api menjadi buaya secara semiotik merupakan simbol yang mengandung makna bahwa Datu Kartamina merupakan orang yang sakti. Hal itu disebabkan tidak sembarang orang dapat melakukan perbuatan tersebut. Selain itu, kemampuan Datu Kartamina yang dapat berubah wujud menjadi seekor buaya kuning merupakan simbol yang secara semiotik mengandung makna bahwa Datu Kartamina merupakan orang yang boleh dikatakan bersekutu dengan jin. Hal itu disebabkan secara alamiah dan ilmiah tidak mungkin manusia dapat berubah wujud menjadi binatang, kecuali hal itu berkat bantuan jin yang pada dasarnya memang bertugas untuk menyesatkan manusia.

\subsection{Kisah Lok Si Naga}

Sebuah keluarga nelayan sungai mempunyai seorang anak laki-laki. Bila mereka pergi bekerja, anaknya tinggal di rumah untuk menjaga rumah.

Pada suatu hari suami istri nelayan itu menunggu ikan-ikan memasuki alat penangkap ikan mereka yang berupa tangguk besar. Sial, seekor pun tidak ada yang mau masuk. Meskipun demikian, mereka tidak mudah putus asa. Tangguknya tetap dimasukkan dan diangkat berulang-ulang tanpa mengenal lelah. Akhirnya ketekunan mereka berhasil juga. Pada waktu mereka mengangkat tangguk mereka untuk kesekian kali, ternyata di dalamnya terlihat ada sebutir telur yang amat besar. Karena ngeri mendapatkan benda ajaib itu, telur itu segera mereka masukkan kembali ke dalam air. Anehnya, setiap kali mereka mengangkat tangguknya, setiap kali ada pula telur itu dan setiap kali segera mereka masukkan kembali ke dalam air. Keadaan ini berulang terus, walaupun telah mereka pindahkan tangguk mereka ke tempat lain. Rupanya telur itu berkeras hati untuk tetap bersama mereka. Akhirnya, karena putus asa telur itu pun dibawa pulang.

Setiba di rumah, dilihatnya anak tersayang mereka sedang tidur. Karena tidak mendapatkan ikan, maka telur itu pun direbusnya. Setelah matang, telur itu mereka makan sebagai lauk teman nasi.

Setelah kenyang, timbullah suatu keajaiban. Kedua suami istri itu perlahanlahan berganti rupa menjadi dua ekor naga yang besar. Keajaiban ini tidak menimpa putra mereka karena ia belum sempat memakan telur itu.

Setelah terjaga dari tidurnya, anak itu pun menjadi sangat ketakutan waktu melihat keadaan orang tuanya. la pun menangis dengan sedihnya. Melihat itu, kedua naga itu segera menjilati pipi putra mereka yang sangat mereka kasihi itu. Setelah anaknya tenang, ayahnya menasihatinya, agar tidak makan telur di atas dulang. Telur itu adalah telur naga putih yang hidup di sungai tempat mereka sering mencari ikan dan siapa saja yang makan telur itu akan menjadi naga seperti mereka. Setelah meninggalkan pesan itu, kedua naga itu pun terjun ke dalam sungai untuk bertempur dengan naga putih, yang telah mengubah ujud mereka. Dua pesan lain yang mereka berikan juga kepada putranya. Apabila timbul darah merah pada air sungai, itu berarti bahwa mereka kalah. Namun, bila timbul darah putih, itu berarti bahwa naga putihlah yang kalah. Tanda hasil pergulatan itu akan terlihat apabila hujan turun rintik-rintik pada hari panas dan pelangi timbul di antara langit dan bumi. Hal itu terlihat dalam kutipan berikut.

"Sepeninggal kedua orang tuanya, anak itu sering terlihat duduk termenung di pinggir sungai sambil memandang ke arah air sungai. Benar saja seperti yang dikatakan oleh orang tuanya, pada suatu hari panas, hujan turun rintikrintik, dan ada pelangi, terlihatlah air sungai 
berubah menjadi putih seperti air susu. Itulah tanda bahwa kedua orang tuanya telah menang dalam perkelahian maut dengan naga putih. Namun, anak itu tidak dapat hidup sendiri tanpa orang tuanya. Oleh karena itu, ia tetap duduk termenung sampai akhir hayatnya" (Yulianto: 75).

\subsubsection{Makna Mitos}

Mitos manusia yang dapat berubah wujud menjadi naga akibat memakan telur naga secara semiotik merupakan simbol yang mengandung makna bahwa manusia jangan sembarangan untuk memakan sesuatu yang bukan merupakan haknya. Selain itu, hal itu juga bermakna terdapat kekuatan gaib dalam telur naga tersebut yang dapat memgubah sosok manusia menjadi naga akibat memakannya. Dengan demikian dapat dipastikan bahwa naga putih sebagai pemiliki telur juga merupakan binatang gaib penguasa alam bawah atau alam air yang merupakan binatang mitos di Kalimantan Selatan.

Pertempuran yang terjadi di sungai antara naga putih dengan dua naga jelmaan nelayan secara semiotik merupakan simbol yang mengandung beberapa makna. Pertama, hal itu merupakan perwujudan rasa dendam kedua suami istri nelayan tersebut terhadap naga putih yang secara tidak langsung telah mengubah wujud mereka menjadi naga. Kedua, hanya boleh ada satu penguasa di sungai tersebut.

\section{Penutup}

Keberadaan mitos-mitos berbasis sungai yang terdapat dalam cerita-cerita rakyat Kalimantan Selatan tidak dapat dilepaskan dari keadaan geografi wilayah Kalimantan Selatan itu sendiri yang memiliki begitu banyak sungai.

Mitos-mitos berbasis sungai yang terdapat dalam cerita-cerita rakyat
Kalimantan Selatan itu antara lain terdapat dalam cerita Kisah Putri Junjung Buih, Asal Mula Terjadinya Sungai Barito, Kisah Sultan Suriansyah Membangun Masjid, Kisah Datu Kartamina, Si Manusia Buaya, dan Kisah Lok Si Naga. Mitos tersebut dapat berupa tokoh manusia atau binatang yang dimitoskan.

Wujud-wujud mitos yang terdapat dalam cerita rakyat Kalimantan Selatan tersebut antara lain berupa kelahiran tokoh Putri Junjung Buih, keberadaan binatang naga serta kehadiran buaya jadijadian dalam masyarakat Kalimantan Selatan.

Makna mitos yang menyatakan bahwa Putri Junjung Buih terlahir dari buih di sungai secara semiotik merupakan simbol yang memiliki makna bahwa penguasa atau raja putri pertama merupakan putra daerah asli Kalimantan Selatan yang kelak akan menurunkan raja-raja di kerajaan-kerajaan yang ada wilayah Kalimantan. Penggambaran atau hadirnya tokoh naga dalam cerita yang dapat berbicara dan bercakap-cakap dengan manusia secara semiotik merupakan simbol yang mengandung makna tentang suatu budaya. Keberadaan buaya jadi-jadian dalam cerita secara semiotik merupakan simbol yang bermakna terjadi hubungan antara manusia dengan jin.

\section{DAFTAR PUSTAKA}

Daeng, Hans J. 2010. Manusia, Kebudayaan, dan Lingkungan: Tinjauan Antropologis. Yogyakarta: Pustaka Pelajar.

Danandjaja, James. 2002. Folklore Indonesia: Ilmu Gosif, Dongeng, dan lain-lain. Jakarta: Grafiti press.

Hasannuddin, WS. 2010. "Keberagaman Akar Sastrawan dan Transformasi Budaya dalam Sastra Indonesia". Makalah disampaikan dalam Seminar Nasional "Sastra 
Indonesia Mutakhir: Kritik dan Keragaman" Temu Sastrawan Indonesia III Kota Tanjung Pinang Provinsi Kepulauan Riau, pada tanggal 28-31 Oktober 2010.

Moleong, Lexy. J. 2010. Metode Penelitian Kualitatif. Bandung: Remaja Rosda Karya.

Napitupulu, ester Lince. 2008. "Tradisi Lisan, Budaya yang Terpinggirkan", dalam Kompas, 22 Desember.

Pradopo, Rachmat Djoko. 2002. Beberapa Teori Sastra, Metode Kritik, dan Penerapannya. Yogyakarta: Pustaka Pelajar.

Rafiek. 2010. Mitos Raja dalam Hikayat Raja Banjar (disertasi). Malang: Universitas Negeri Malang.

Saefuddin. 2004. Struktur Mite dalam Sastra Lisan Banjar.Banjarbaru: Balai Bahasa Banjarmasin.

Semi. M. Atar. 2012. Metode Penelitian Sastra. Bandung: Angkasa Jaya.
Sobur, Alex. 2001.Analisis Teks Media (Suatu Pengantar untuk Analisis Wacana, Analisis Semiotik, dan Analisis Framing). Jakarta: Rosda

Sunarto. 2001. Metode Penelitian Ilmuilmu Sosial dan Pendidikan. Surabaya: Unesa University Press.

Suryadikara, Fudiat. dkk. 2002. Mitos dalam Hikayat Lambung Mangkurat. Banjarmasin: Proyek Pembinaan dan Pengembangan Bahasa dan Sastra Indonesia dan Daerah.

Tim Penyusun. 2014. Kamus Besar Bahasa Indonesia. Jakarta: Balai Pustaka.

Wouden, Van F.A.E. 1985. Klien, Mitos, dan Kekuasaan. Jakarta: Grafiti Perss.

Yulianto, Agus dkk. 2015. Pemetaan Sastra di Kalimantan Selatan: Cerita Rakyat. Banjarbaru: Balai Bahasa Kalimantan Selatan. 